\title{
Inhibition of CD38 with the Thiazoloquin(az)olin(on)e 78c Protects the Heart against Postischemic Injury
}

\author{
James Boslett, Nikhil Reddy, Yasmin A. Alzarie, and Jay L. Zweier \\ Department of Internal Medicine, Division of Cardiovascular Medicine, Davis Heart and Lung Research Institute, College of \\ Medicine, The Ohio State University, Columbus, Ohio
}

Received October 22, 2018; accepted January 10, 2019

\section{ABSTRACT}

Inhibition of and genetic deletion of the $\mathrm{NAD}(\mathrm{P})^{+}$hydrolase $[\mathrm{NAD}(\mathrm{P})$ ase] $\mathrm{CD} 38$ have been shown to protect against ischemia/reperfusion (I/R) injury in rat and mouse hearts. CD38 has been shown to enhance salvage of NADP $(H)$, which in turn prevents impairment of endothelial nitric oxide synthase function, a hallmark of endothelial dysfunction. Despite growing evidence for a role of CD38 in postischemic injury, until recently there had been a lack of potent CD38 inhibitors. Recently, a new class of thiazoloquin(az)olin(on)e compounds were identified as highly potent and specific CD38 inhibitors. Herein, we investigate the ability of one of these compounds, 78c, to inhibit CD38 and protect the heart in an ex vivo model of myocardial I/R injury. The potency and mechanism of CD38 inhibition by $78 \mathrm{c}$ was assessed in vitro using recombinant CD38. The dose-dependent tissue uptake
\end{abstract}

of $78 \mathrm{c}$ in isolated mouse hearts was determined, and high tissue permeability of $78 \mathrm{c}$ was observed when delivered in perfusate. Treatment of hearts with $78 \mathrm{c}$ was protective against both postischemic endothelial and cardiac myocyte injury, with preserved nitric oxide synthase-dependent vasodilatory and contractile function, respectively. Myocardial infarction was also significantly decreased in 78c-treated hearts, with preserved levels of high-energy phosphates. Protective effects peaked at $10 \mu \mathrm{M}$ treatment, and similar protection without toxicity was seen at 5-fold higher doses. Overall, $78 \mathrm{c}$ was shown to be a potent and biologically active CD38 inhibitor with favorable tissue uptake and marked protective effects against I/R injury with enhanced preservation of contractile function, coronary flow, and decreased infarction.

\section{Introduction}

Recently, much attention has focused on the discovery (Kellenberger et al., 2011; Blacher et al., 2015) and development of CD38 inhibitors (Moreau et al., 2013; Becherer et al., 2015; Haffner et al., 2015; Li et al., 2015). This is due to the wide variety of physiologic and pathologic conditions influenced by CD38 (Malavasi et al., 2008; Quarona et al., 2013). As an enzyme, CD38 primarily functions as an $\mathrm{NAD}(\mathrm{P})$ ase, hydrolyzing $\mathrm{NAD}(\mathrm{P})^{+}$to $\left(2^{\prime}\right.$-phospho- $) \mathrm{ADP}$ ribose [(2'-P-)ADPR] (Berthelier et al., 1998). CD38 is also an ADP-ribosyl cyclase, producing in lesser amounts (2'-phospho-)cyclic ADP ribose [(2'-P)-cADPR] (Berthelier et al., 1998). CD38 can also convert $\mathrm{NADP}^{+}$to nicotinic acid adenine dinucleotide phosphate (NAADP) under acidic conditions in the presence of nicotinic acid (Chini et al., 2002). CD38 is also an NAADPase, hydrolyzing NAADP to 2'-P-ADPR (Graeff et al., 2006) (see Fig. 1 for a summary of CD38 enzymatic functions). Recently, we discovered that activation of CD38 in the ischemic heart is an important mechanism of myocardial and endothelial $\mathrm{NADP}(\mathrm{H})$ depletion

This work was supported by the National Institutes of Health National Heart, Lung, and Blood Institute [Awards R01HL131941 and R01HL135648]. https://doi.org/10.1124/jpet.118.254557.
(Reyes et al., 2015; Boslett et al., 2018a). This endothelial NADP (H) depletion was shown to severely impair endothelial nitric oxide synthase (eNOS) function, limiting endothelium-dependent vasodilation in the postischemic heart.

This novel finding led to our search for better CD38 inhibitors than those used previously, with a focus on potency and efficient cellular uptake. Until recent years, there was a lack of high-affinity CD38 inhibitors suitable for therapeutic use, with known inhibitors such as $\alpha$-NAD requiring millimolar levels (Reyes et al., 2015). We have observed that the natural product flavonoid, luteolinidin, inhibits CD38 in sub-10 $\mu \mathrm{M}$ concentrations and exerts potent cardiac protection after ischemia/reperfusion ( $\mathrm{I} / \mathrm{R}$ ) in isolated rat hearts (Boslett et al., 2017). However, the multiple polar phenolic groups of this flavonoid precluded direct tissue uptake when delivered in buffer. Rather, liposomal formulations of luteolinidin were necessary to achieve rapid tissue uptake and therapeutic levels. Although luteolinidin was highly effective in conferring myocardial protection, its requirement for liposomal packaging would limit possible future uses and routes of administration in its translation to clinical use. For simple direct administration, an inhibitor would optimally have both high potency and bioavailability, respectively, limiting off-target effects and facilitating effective delivery.

ABBREVIATIONS: ADPR, ADP ribose; cADPR, cyclic ADP ribose; CF, coronary flow; $\varepsilon$-NAD, nicotinamide 1, $N^{6}$-ethenoadenine dinucleotide; eNOS, endothelial nitric oxide synthase; HPLC, high-performance liquid chromatography; I/R, ischemia/reperfusion; MPA, mobile phase A; MPB, mobile phase B; NAADP, nicotinic acid adenine dinucleotide phosphate; NO, nitric oxide; NOS, nitric oxide synthase; rCD38, recombinant human CD38; SPE, solid-phase extraction; SXAW, Strata-X-AW; TTC, 2,3,5-triphenyltetrazolium chloride; $V_{\text {max }}$, maximum rate of reaction; WT, wild type. 


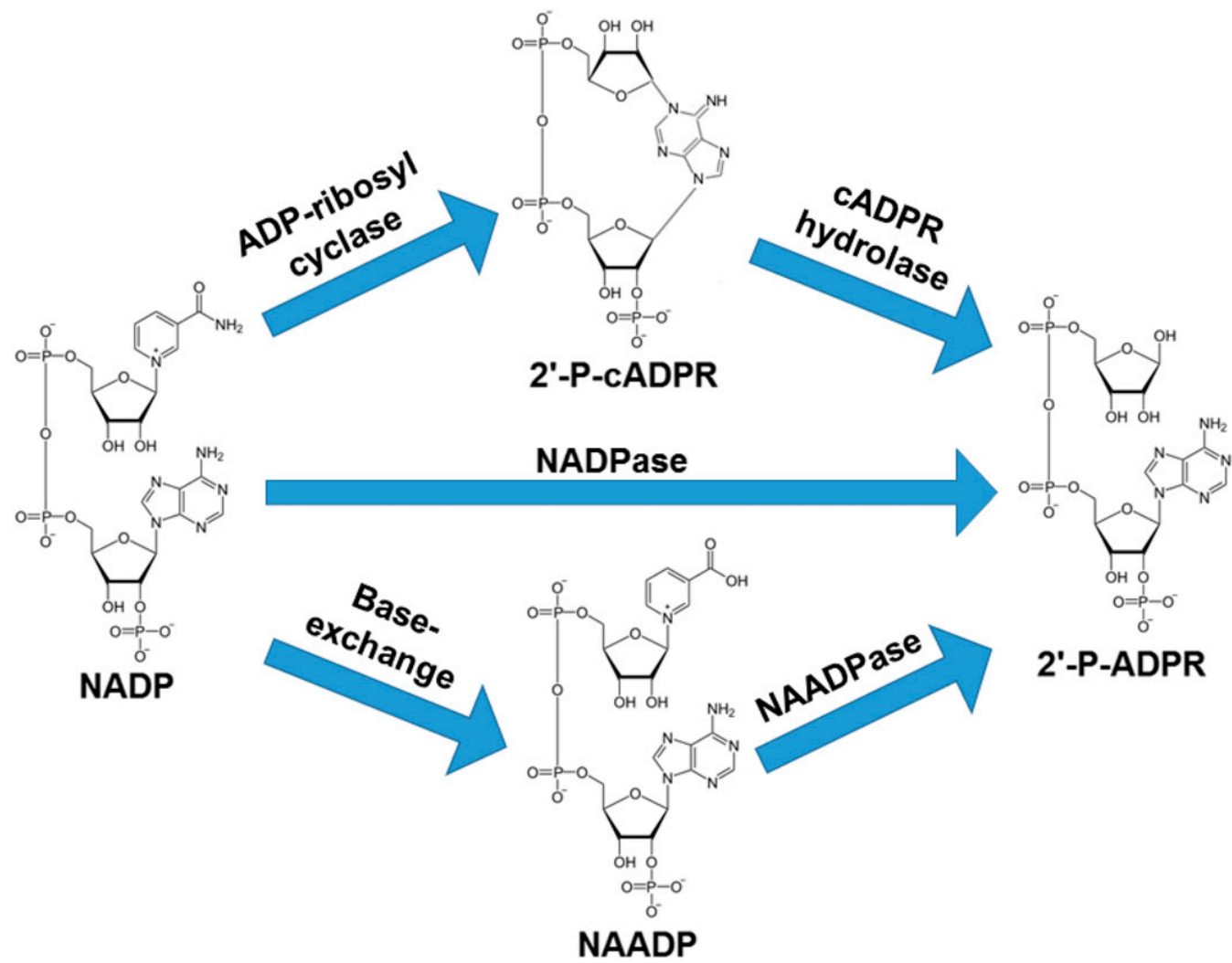

Fig. 1. Enzymatic functions of CD38 with NADP as substrate. CD38 has been shown to primarily function as an NADPase (NADP hydrolase) converting NADP to 2'-P-ADPR. A small fraction of NADP is converted by CD38 to potent calcium signaling molecule 2'-P-cADPR as a part of its ADP-ribosyl cyclase function. The formed $2^{\prime}$-P-cADPR can then be hydrolyzed to $2^{\prime}$-P-ADPR (cADPR hydrolase). At acidic $\mathrm{pH}$ and in the presence of nicotinic acid, CD38 can convert NADP to another potent calcium-mobilizing second messenger, NAADP, in the base-exchange reaction. In this exchange, nicotinamide of NADP is replaced with nicotinic acid. Formed NAADP can be broken down to 2'-P-ADPR in an NAADP hydrolase reaction (NAADPase).

One promising family of compounds recently identified as CD38 inhibitors are the thiazoloquin(az)olin(on)es. These were shown to have efficacy for in vitro CD38 inhibition down to the low nanomolar range, with favorable pharmacokinetics (Becherer et al., 2015). In this study, we test the cardioprotective efficacy of the lead compound in this class of thiazoloquin(az)olin(on)es (78c), which was selected as most promising for translation. Initially, studies were performed to determine the dosedependent potency of CD38 inhibition using an established in vitro assay (Graeff and Lee, 2013). We then determined the total and free tissue levels of $78 \mathrm{c}$ in perfused mouse hearts after dose-dependent treatment with 78c. Further studies were performed in the isolated mouse heart model of global $\mathrm{I} / \mathrm{R}$ injury. Measurements in myocardial tissue of CD38 substrates $\mathrm{NAD}(\mathrm{P})^{+}$and its CD38-derived enzymatic products $\left(2^{\prime}-\mathrm{P}-\right) \mathrm{ADPR}$ were performed that demonstrated effective CD38 inhibition with 78c delivery. Lastly, myocardial protection was evaluated in this model, where it was demonstrated that CD38 inhibition confers marked cardiac protection with preserved endothelial and myocyte function with decreased infarction.

\section{Materials and Methods}

All chemicals and reagents were purchased from Sigma, with the exception of CD38 inhibitor 78c, which was obtained as a gift from GlaxoSmithKline, and recombinant CD38, which was a generous gift from Dr. Hon-Cheung Lee (Peking University, Shenzhen, China).

Animals. All mice used for experiments were in the age range of 4-6 months. C57Bl/6J mice were obtained from Jackson Laboratories.
All animal protocols were approved by the Institutional Animal Care and Use Committee of The Ohio State University and conformed to the National Institutes of Health Guide for the Care and Use of Laboratory Animals.

CD38 Activity Assay. CD38 has been reported to function primarily as an $\mathrm{NAD}(\mathrm{P})^{+}$ase through its hydrolysis of $\mathrm{NAD}(\mathrm{P})^{+}$to $2^{\prime}-\mathrm{P}-\mathrm{ADPR}$. To measure this enzyme activity specifically, a substrate analog of $\mathrm{NAD}^{+}$, nicotinamide $1, \mathrm{~N}^{6}$-ethenoadenine dinucleotide $(\varepsilon-\mathrm{NAD})$, was used (Graeff and Lee, 2013; Boslett et al., 2017). For pure protein experiments, recombinant human CD38 (rCD38) was used for measuring CD38 activity in vitro. $\mathrm{rCD} 38(0.1 \mu \mathrm{g} / \mathrm{ml})$, truncated of its single pass transmembrane domain, $\mathrm{N}$-glycosylation sites, and $\mathrm{N}$-terminal tail, was added to a $100 \mu \mathrm{l}$ reaction mixture containing varying concentrations of $\varepsilon$-NAD (5-100 $\mu \mathrm{M})$ and/or 78c (0-40 nM). Fluorescence was monitored at emission and excitation wavelengths of 300 and $410 \mathrm{~nm}$, respectively, for the conversion of $\varepsilon-\mathrm{NAD}$ to the strongly fluorescent product $\varepsilon$-ADPR on a Molecular Devices SpectraMax M5 plate reader. Lineweaver-Burk analysis was performed, in conjunction with analysis using a nonlinear regression program (GraphPad Prism), to determine the mode of enzyme inhibition and estimates of the maximum rate of reaction $\left(\mathrm{V}_{\max }\right)$, the Michaelis constant $\left(K_{\mathrm{m}}\right)$, and the inhibitory constant $\left(K_{\mathrm{i}}\right)$.

Isolated Heart Perfusion. Isolated heart experiments were performed as described previously (Reyes et al., 2015; Boslett et al., 2018a). Male C57Bl/6 mice weighing 25-30 g were heparinized and injected with $100 \mathrm{mg} / \mathrm{kg}$ ketamine and $15 \mathrm{mg} / \mathrm{kg}$ xylazine intraperitoneally. Hearts were excised, cleaned of nonmyocardial tissue, cannulated via the aorta, and perfused retrogradely in Langendorff mode with Krebs-Henseleit buffer $(119 \mathrm{mM} \mathrm{NaCl}, 17 \mathrm{mM}$ glucose, $2 \mathrm{mM}$ sodium pyruvate, $25 \mathrm{mM} \mathrm{NaHCO}_{3}, 5.9 \mathrm{mM} \mathrm{KCl}, 1.2 \mathrm{mM} \mathrm{MgCl}_{2}$, $2.5 \mathrm{mM} \mathrm{CaCl}_{2}$, and $0.5 \mathrm{mM} \mathrm{NaEDTA}$ ). A polyvinylchloride balloon 
connected to a pressure transducer (ADInstruments) was placed in the left ventricle to measure the left ventricular developed pressure, systolic pressure, left ventricular end diastolic pressure, heart rate, and rate of change of pressure over time. An inline flow probe (Transonic) measured coronary flow (CF). For drug delivery experiments, $78 \mathrm{c}$ was initially dissolved in $100 \%$ DMSO and diluted to final concentrations using Krebs-Henseleit buffer. To keep delivery solvent consistent, a final concentration of $0.1 \%$ DMSO was maintained for all experiments. Solutions of $78 \mathrm{c}$ were delivered at 1:20 of $\mathrm{CF}$ with a Harvard pump through a perfusion sidearm located directly above the heart.

Endothelial Permeabilization for NAD(P)(H) Measurements. A method to permeabilize the endothelium of perfused mouse hearts was performed to collect endothelial metabolites (Giraldez et al., 2000; Reyes et al., 2015; Boslett et al., 2018a). Hearts were subjected to either control perfusion or 30 minutes of ischemia, followed by 30 minutes of reperfusion, and a 7.5- $\mu \mathrm{l}$ bolus of $0.25 \%$ Triton X-100 in PBS was infused through a septum-capped sidearm directly above the perfusion cannula using a 10- $\mu$ l Hamilton syringe. Coronary effluent $(1 \mathrm{ml})$ was immediately collected and snap frozen in liquid nitrogen. Only effluent samples from hearts with normal post-Triton X-100 contractile and smooth muscle function, as well as completely eliminated endothelial function, were studied. Normal function was defined as hearts displaying greater than $80 \%$ of the pre-Triton $\mathrm{X}-100$ rate-pressure product, a maintained response to nitric oxide (NO)-donor sodium nitroprusside (greater than $90 \%$ of pre-Triton X-100 response), and less than a $5 \%$ increase in CF in response to bolus injections of endothelium-dependent vasodilators acetylcholine $(50 \mathrm{pmol})$ or bradykinin ( $1 \mathrm{nmol})$.

Solid-Phase Extraction of NADP(H) from Coronary Effluents. Frozen coronary effluents were further purified and enriched using anion-exchange solid-phase extraction (SPE) with Strata-X-AW (SXAW) cartridges (Phenomenex). SXAW cartridges were conditioned with $1 \mathrm{ml}$ methanol, $1 \mathrm{ml} 2 \%$ acetic acid in 25\% methanol, and $1 \mathrm{ml}$ water. Prior to loading samples to the SXAW cartridges, sample $\mathrm{pH}$ was adjusted to $\sim 4$ to 5 with acetic acid. Samples were then applied to the SPE cartridges twice under light vacuum. After washing with $1 \mathrm{ml}$ water and $1 \mathrm{ml} \mathrm{40 \%} \mathrm{methanol,} \mathrm{metabolites} \mathrm{were} \mathrm{eluted} \mathrm{from} \mathrm{the} \mathrm{SPE}$ cartridges with $10 \% \mathrm{NH}_{4} \mathrm{OH}$ in water. These samples were then frozen and lyophilized. Dried samples were then resuspended in $100 \mu \mathrm{l}$ of $200 \mathrm{mM}$ potassium cyanide, $60 \mathrm{mM}$ potassium hydroxide, and $1 \mathrm{mM}$ diethylenetriaminepentaacetic acid for high-performance liquid chromatography (HPLC) analysis of $\mathrm{NAD}(\mathrm{P})(\mathrm{H})$.

HPLC Analysis of Pyridine Nucleotides. Pyridine nucleotides were measured by HPLC with fluorescence detection as detailed previously (Reyes et al., 2015; Boslett et al., 2017). In this method, cyanide ion from potassium cyanide in basic solution is used to derivatize $\mathrm{NAD}^{+}$and $\mathrm{NADP}^{+}$to stable, fluorescent analytes, allowing for measurements of both the oxidized and reduced nucleotides in one chromatographic run (Klaidman et al., 1995). Resuspended samples from endothelium-permeabilized hearts were injected onto a Supelcosil LC-18-T column $(25 \mathrm{~cm} \times 4.6 \mathrm{~mm} \times 5 \mu \mathrm{m})$ with mobile phase A (MPA) of $200 \mathrm{mM}$ ammonium acetate ( $\mathrm{pH} 5.8$ ) and mobile phase B (MPB) of $200 \mathrm{mM}$ ammonium acetate ( $\mathrm{pH} 5.8$ ) in $50 \%$ methanol. Separation was achieved with an initial flow rate of $1.0 \mathrm{ml} / \mathrm{min}$ consisting of $8 \% \mathrm{MPB}$ and a linear methanol gradient $(0.4 \%$ per minute for 25 minutes). Analytes were detected via fluorescence spectroscopy (excitation wavelength of $330 \mathrm{~nm}$; emission wavelength of $460 \mathrm{~nm}$ ). Peaks were assigned by coelution with analytical standards, and quantitation was performed with use of standard curves prepared from analytical standards.

SPE of Nucleotides from Heart Homogenates. Nucleotides including ATP, ADP, AMP, 2'-P-ADPR, and NAD(P) were extracted from heart tissue with five volumes of $0.1 \mathrm{~N} \mathrm{HCl}$. The resulting homogenate was centrifuged to pellet insoluble materials and then filtered with a 3000 molecular weight cutoff filter to obtain a nucleotide-containing filtrate. This filtrate was further purified using anion-exchange SPE with SXAW cartridges (Phenomenex). Prior to sample loading, cartridges were conditioned with $1 \mathrm{ml}$ methanol, $1 \mathrm{ml} 2 \%$ acetic acid in $25 \%$ methanol, and $1 \mathrm{ml}$ water. Heart filtrates were then applied to the SPE cartridges under light vacuum. After washing with $1 \mathrm{ml}$ water, nonpolar metabolites were eluted with $1 \mathrm{ml} \mathrm{40 \%} \mathrm{methanol} \mathrm{and} \mathrm{nucleotides} \mathrm{with} 10 \%$ $\mathrm{NH}_{4} \mathrm{OH}$ in water. Eluates were immediately frozen in liquid nitrogen, lyophilized, and then resuspended in $100 \mu \mathrm{l}$ deionized water for HPLC analysis.

HPLC Analysis of Nucleotides. HPLC of nucleotides [ATP, ADP, AMP, 2'-P-ADPR, NAD(P)] was measured using ion-pairing reversed phase HPLC. Ion pairing was essential to obtain adequate retention time and separation using reversed phase HPLC. HPLC was carried out in the reversed phase using a two-pump system with a Supelcosil LC-18-T column $(25 \mathrm{~cm} \times 4.6 \mathrm{~mm} \times 5 \mu \mathrm{m})$ and matching guard column. Detection of nucleotides was performed with absorbance at $254 \mathrm{~nm}$. The composition of MPA was $65 \mathrm{mM}$ potassium phosphate/10 $\mathrm{mM}$ tetrabutylammonium hydrogen sulfate (ion-pairing agent) in water ( $\mathrm{pH} 5.0$ ) and MPB was identical except for a final concentration of $50 \%$ acetonitrile. The gradient elution of nucleotides was performed at constant flow of $1 \mathrm{ml} / \mathrm{min}$. The gradient was performed as follows: 0-10 minutes, $0 \%-16 \%$ MPB; 10-20 minutes, $16 \%-60 \%$ MPB; $20-25$ minutes, $60 \%$ MPB; 25-32 minutes, 60\%-0\% MPB; and 32-42 minutes, 0\% MPB. Concentrations of nucleotides in heart samples were derived from standard curves prepared from the analysis of pure standards, which, in the case of $\left(2^{\prime}-\mathrm{P}-\mathrm{ADPR}\right)$, were prepared from the reaction of $\mathrm{rCD} 38$ with pure $\mathrm{NAD}(\mathrm{P})^{+}$. For all samples, HPLC analysis was performed with and without sample spiking to ensure proper peak identification.

HPLC of 78c. Compound 78c was extracted from heart tissue in either ice-cold $0.1 \mathrm{~N} \mathrm{HCl}$ in $20 \%$ DMSO for measurement of total levels or ice-cold PBS for measurement of free levels. Homogenates were first centrifuged to pellet insoluble debris and were then filtered to remove protein interferences prior to HPLC. Fluorescence detection of $78 \mathrm{c}$ was used with excitation and emission wavelengths of 286 and $388 \mathrm{~nm}$, respectively. Reversed phase HPLC was performed with a Waters Atlantis C18 column with a MPA of $100 \mathrm{mM}$ potassium phosphate $(\mathrm{pH} \mathrm{7.0)}$ and a MPB of $100 \mathrm{mM}$ potassium phosphate $(\mathrm{pH} 7.0)$ in $50 \%$ acetonitrile at a total flow of $1.2 \mathrm{ml} / \mathrm{min}$. The gradient elution of $78 \mathrm{c}$ was performed with an initial percentage of MPB of $20 \%$. Between 0 and 15 minutes, the percentage of MPB increased from $20 \%$ to $100 \%$. Elution at $100 \%$ B occurred from 15 to 20 minutes, with the return of MPB to a baseline level of $20 \%$ from 20 to 22.50 minutes. The run ended after a 5-minute restabilization period from 22.50 to 27.50 minutes at $20 \%$ B. Peak identification and quantitation was performed using the same batch of $78 \mathrm{c}$ standard used for isolated heart experiments.

Myocardial Infarct Size Measurement. Ex vivo myocardial infarction was measured by 2,3,5-triphenyltetrazolium chloride (TTC) staining of heart sections, as reported previously (Boslett et al., 2018a). The heart was immediately removed after $I / R$ and frozen for 20 minutes for hardening. The heart was then serially sectioned into transverse slices $(1 \mathrm{~mm})$ by a heart slicer (Zivic Laboratories) and incubated in $1.5 \%$ TTC in PBS for 15 minutes at $37^{\circ} \mathrm{C}$ to demarcate the viable (brick red) and infarcted (pale) myocardium. Heart slices were then fixed overnight in $10 \%$ neutral-buffered formaldehyde for improved color contrast and were digitally imaged. Computerized planimetry (with image-analysis software MetaVue, version 6.0) of each section was used to determine the percentage of infarction from the total cross-sectional area of the left ventricle.

Statistical Analysis. Results are expressed as the mean \pm S.E. Statistical significance was determined by ANOVA (followed by the Holm-Sidak test) for multiple groups. Paired or unpaired $t$ tests were used for comparison between two groups. In the case of timedependent data, ANOVA with two-way repeated measures was used to determine significance. 
A<smiles>COCCO[C@H]1CC[C@H](Nc2cc(=O)n(C)c3ccc(-c4cncs4)cc23)CC1</smiles>

B
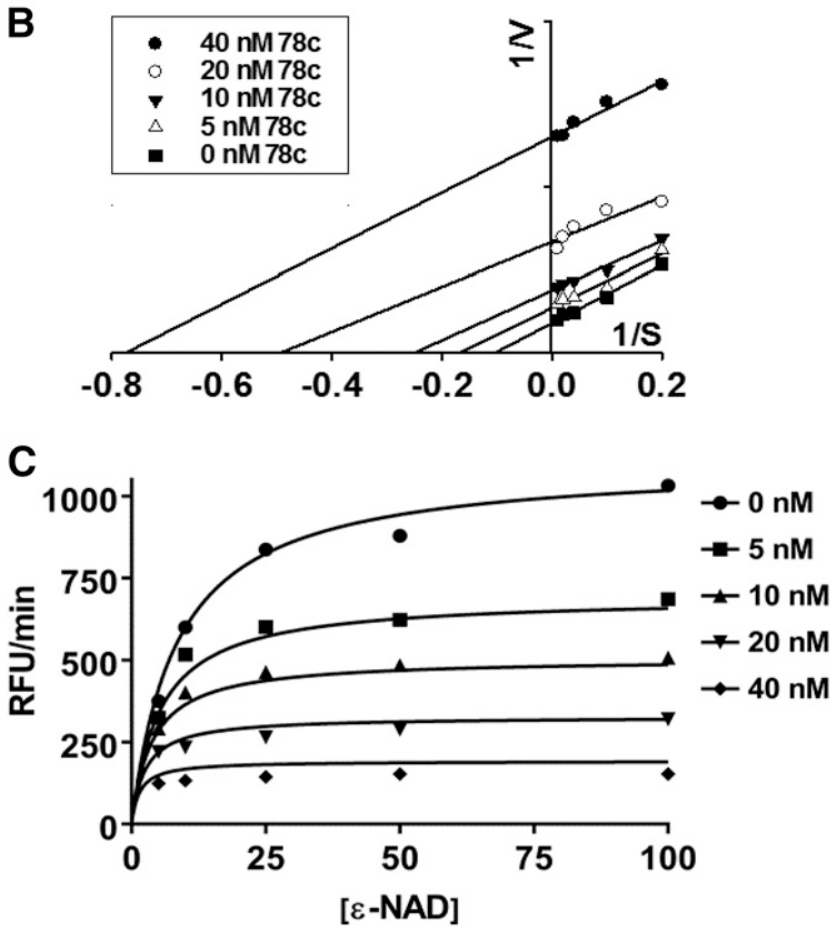

Fig. 2. Characterization of CD38 inhibition by 78c. (A) Structure of CD38 inhibitor 78c. Maximum rates of reaction were measured for the CD38catalyzed conversion of substrate $\varepsilon$-NAD $(0-100 \mu \mathrm{M})$ to fluorescent etheno-ADPR in the presence of $78 \mathrm{c}(0-40 \mathrm{nM})$. (B) inhibition data analyzed by Lineweaver-Burk analysis showed uncompetitive inhibition of CD38, as increasing the concentration of 78c decreased both the $V_{\max }$ and apparent $K_{\mathrm{m}}$. (C) Nonlinear regression of $78 \mathrm{c}$ inhibition data fit to the equation for uncompetitive inhibition enabled determination of the inhibitor constant $\left(K_{\mathrm{i}}\right)$ of $8.4 \mathrm{nM}$. Each data point represents the average of four to six experiments. RFU, relative fluorescence unit.

\section{Results}

Potency of CD38 Inhibition. Compound 78c (Fig. 2A) was tested for its potency against rCD38. $\mathrm{rCD} 38(0.1 \mu \mathrm{g} / \mathrm{ml})$ was incubated with varying concentrations of substrate etheno-NAD (5-100 $\mu \mathrm{M})$ and $78 \mathrm{c}$ in the range of $0-40 \mathrm{nM}$, with the conversion of $\varepsilon$-NAD to $\varepsilon$-ADPR monitored by an increase in fluorescence. Inhibition data fit strongly to an uncompetitive inhibition model, with a $K_{\mathrm{i}}$ of $\sim 9 \mathrm{nM}$ for human CD38. An uncompetitive inhibition model was determined by carefully measuring $\mathrm{V}_{\max }$ and $K_{\mathrm{m}}$ with the different combinations of substrate and inhibitor concentrations, and then modeling the inhibition data with Lineweaver-Burk analysis (Fig. 2B) and nonlinear regression analysis (Fig. 2C). Consistent with uncompetitive inhibition, both $\mathrm{V}_{\max }$ and apparent $K_{\mathrm{m}}$ decreased with increasing inhibitor concentration, producing parallel lines with different $X$ and $Y$ intercepts
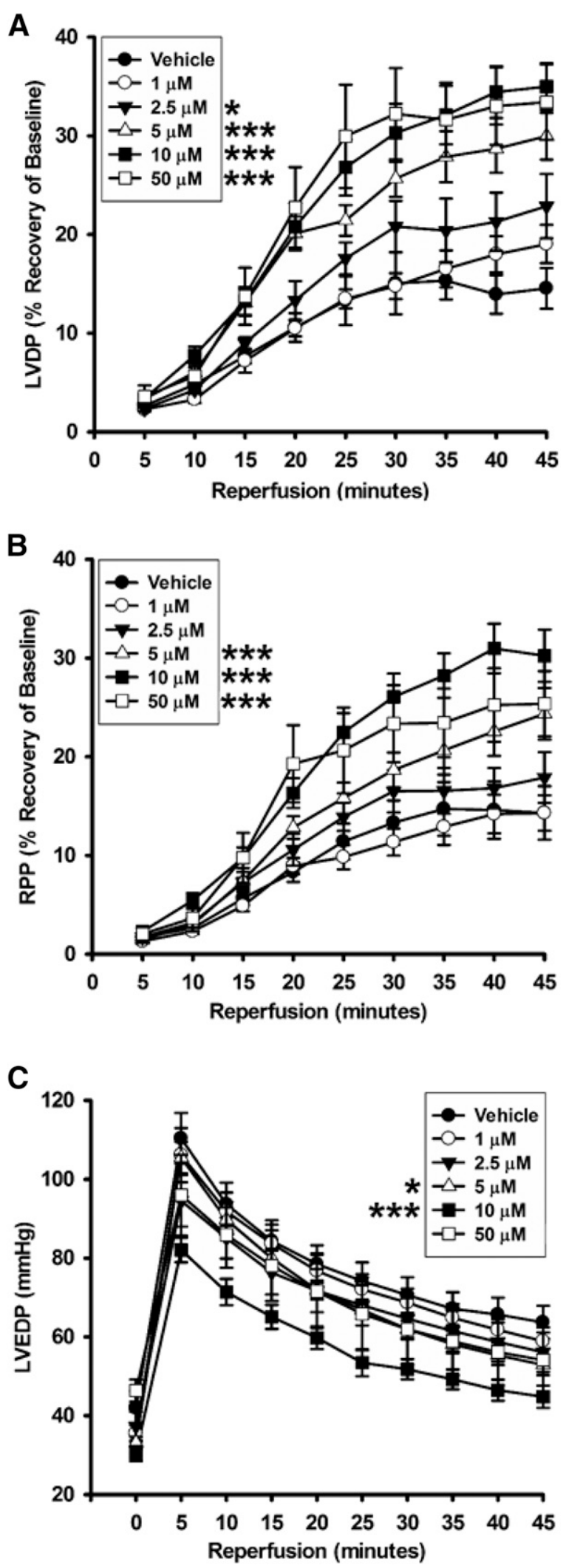

Fig. 3. Contractile function recovery after ischemia. The dose-dependent effect of $78 \mathrm{c}$ on the recovery of contractile function was measured through the first 45 minutes of reperfusion after 30 minutes of global ischemia. 78c was protective of LVDP from 2.5 to $50 \mu \mathrm{M}$ (A), of RPP from 5 to $50 \mu \mathrm{M}$ (B), and of LVEDP for 5 and $10 \mu \mathrm{M}(\mathrm{C})$. $78 \mathrm{c}$ delivered at $1 \mu \mathrm{M}$ was not protective of any physiologic parameter measured. $* P<0.05$; *** $P<0.001$ (mean \pm S.E.M., $n=5-9$ ). LVDP, left ventricular developed pressure; LVEDP, left ventricular end diastolic pressure; RPP, ratepressure product. 
TABLE 1

Recovery of cardiac function in 78c-treated hearts after 30-minute ischemia/30-minute reperfusion

Values are presented as the mean \pm S.E.M. $(n=5-9)$. Values for LVDP and RPP are shown as the percentage of recovery.

\begin{tabular}{|c|c|c|c|c|}
\hline Treatment & LVDP & RPP & LVEDP & $\mathrm{CF}$ \\
\hline$\mu M$ & $\%$ & $\%$ & $\mathrm{~mm} \mathrm{Hg}$ & $\mathrm{ml} / \mathrm{min}$ \\
\hline Vehicle & $14.5 \pm 2.1$ & $14.3 \pm 2.7$ & $63.7 \pm 4.2$ & $69.3 \pm 3.3$ \\
\hline 1 & $19.0 \pm 1.9$ & $14.3 \pm 1.8$ & $58.9 \pm 3.5$ & $64.1 \pm 6.7$ \\
\hline 2.5 & $22.9 \pm 3.2^{*}$ & $17.9 \pm 2.6$ & $56.1 \pm 5.0$ & $75.5 \pm 4.9$ \\
\hline 5 & $30.0 \pm 2.4^{* *}$ & $24.4 \pm 2.6^{* *}$ & $52.9 \pm 2.6^{*}$ & $76.5 \pm 3.0^{*}$ \\
\hline 10 & $35.0 \pm 2.4^{* *}$ & $30.2 \pm 2.6^{* *}$ & $44.8 \pm 2.8^{* *}$ & $80.9 \pm 3.2^{*}$ \\
\hline 50 & $33.4 \pm 3.8^{* *}$ & $25.4 \pm 3.3^{* *}$ & $54.1 \pm 8.3^{*}$ & $80.6 \pm 5.9^{*}$ \\
\hline
\end{tabular}

The dose-dependent effects of 78c treatment on postischemic LVDP, RPP, LVEDP, and $C F$ in hearts subjected to I/R are shown. The recoveries of LVDP, RPP, and CF were increased, and LVEDP decreased, after 30-minute ischemia/30-minute reperfusion with $78 \mathrm{c}$ treatment in a dose-dependent manner. LVDP, left ventricular developed pressure; LVEDP, left ventricular end diastolic pressure; RPP, ratepressure product.

$* P<0.05 ; * * P<0.001$.

representing $-1 / K_{\mathrm{m}}$ and $1 / \mathrm{V}_{\max }$, respectively, in a Lineweaver-Burk plot.

Recovery of Contractile Function. The ability of $78 \mathrm{c}$ to confer postischemic cardiac protection was tested dosedependently using $1,2.5,5,10$, and $50 \mu \mathrm{M}$ compound. We initially tested a dose of $10 \mu \mathrm{M}$, as we reasoned that this would likely well exceed the level required to achieve full CD38 inhibition throughout the postischemic period. Hearts were treated at 1:20 of CF with $200 \mu \mathrm{M} 78 \mathrm{c}$ solution for 10 minutes prior to a 30-minute ischemia. We found that the recoveries of the left ventricular developed pressure and the rate-pressure product in each of the $10 \mu \mathrm{M}$-treated hearts were over double that of the vehicle-treated hearts (Fig. 3; Table 1). Consistent with this, left ventricular end diastolic pressure, a measure of diastolic relaxation, was lower in the $10 \mu \mathrm{M} 78 \mathrm{c}-$ treated hearts.

With significant protection of cardiac function found for a $10-\mu \mathrm{M} 78 \mathrm{c}$ dose, we performed further studies to determine the minimum cardiac protective dose of $78 \mathrm{c}$ and the dose dependence of cardiac protection. At $1 \mu \mathrm{M} 78 \mathrm{c}$, cardiac protection was completely lost, with very similar postischemic function compared with hearts receiving vehicle control. Thus, it appeared that the protective effects of 78c likely started somewhere in the range of 1-10 $\mu \mathrm{M}$. Consistent with this, intermediate levels of protection of cardiac function were observed with infusions of 2.5 and $5 \mu \mathrm{M} 78 \mathrm{c}$ (Fig. 3; Table 1). We also increased the $78 \mathrm{c}$ dose to a final concentration of $50 \mu \mathrm{M}$ to determine whether there was any additive protective effect above the $10 \mu \mathrm{M}$ dose or whether any toxicity was observed. At $50 \mu \mathrm{M}$, cardiac protection was very similar to that observed with $10 \mu \mathrm{M} 78 \mathrm{c}$, indicating that the protective effects of 78c were maximal at $10 \mu \mathrm{M} 78 \mathrm{c}$. Importantly, we did not find toxicity on acute delivery of $50 \mu \mathrm{M} 78 \mathrm{c}$ while still maintaining cardiac protection equal to that seen with $10 \mu \mathrm{M}$ 78c. Thus, 78c provides cardiac protection in a fairly broad range of doses with no apparent cardiac toxicity.

Total and Nitric Oxide Synthase-Dependent CF. We questioned how CD38 inhibition with 78c might impact the severe reduction in total and nitric oxide synthase (NOS)dependent CF seen with I/R (Dumitrescu et al., 2007; Reyes et al., 2015; Boslett et al., 2018a). Total CF was measured throughout the preischemic period and through 120 minutes of reperfusion after a 30-minute ischemic period. We found that $\mathrm{CF}$ through the first 45 minutes of reperfusion was significantly higher $(P<0.05)$ in hearts treated with 5 and $10 \mu \mathrm{M} 78 \mathrm{c}$ compared with those treated with the vehicle. Lower doses of 1 and $2.5 \mu \mathrm{M} 78 \mathrm{c}$ did not have a significant protective effect on total CF (Fig. 4A).

As a component of total CF, we also measured NOSdependent $\mathrm{CF}$ with acute $N_{\omega}$-nitro-L-arginine methyl ester (an NOS inhibitor) infusions to hearts after 30 minutes of reperfusion. In vehicle-treated hearts undergoing I/R, 75\% of baseline NOS-dependent CF was lost. However, 78c treatment dose-dependently preserved NOS-dependent CF after
A

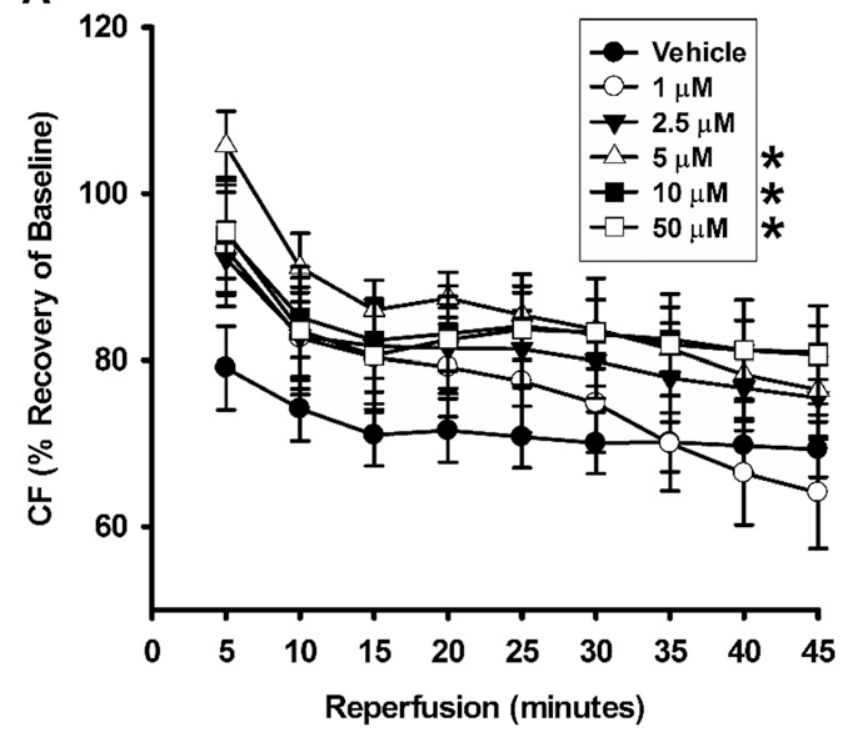

B

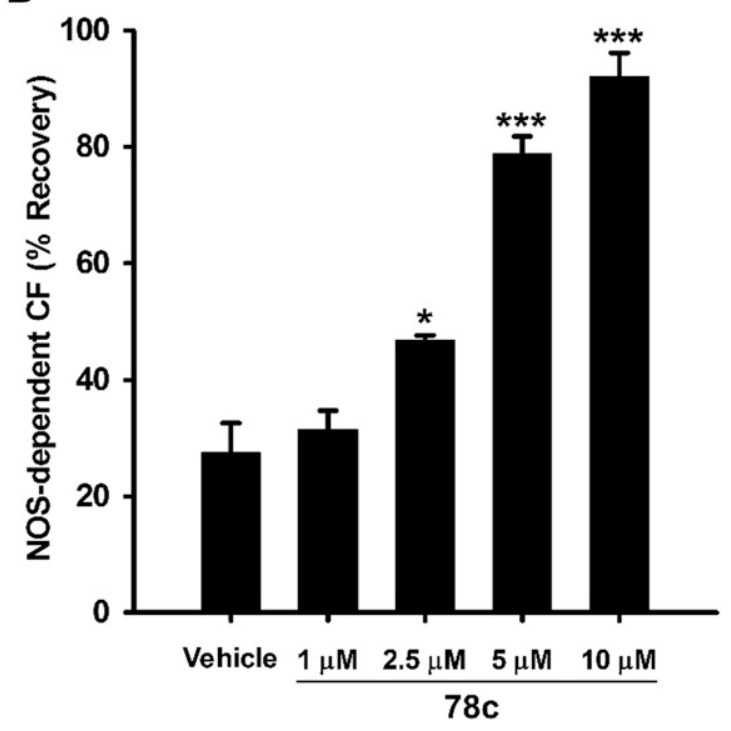

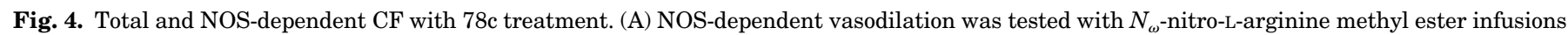

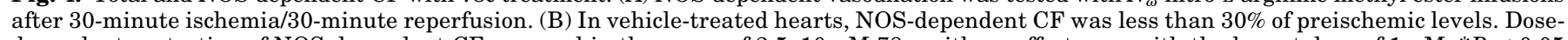

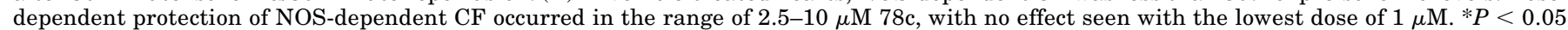
(mean \pm S.E.M., $n=6-9$ ). 


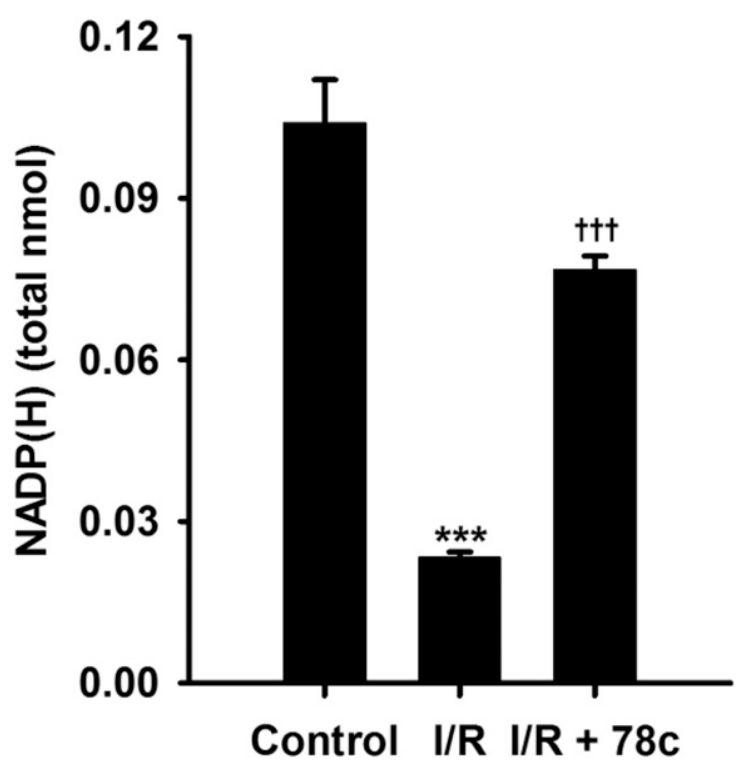

Fig. 5. Endothelial levels of $\mathrm{NADP}(\mathrm{H})$ in WT hearts. Endothelial levels of $\operatorname{NADP}(\mathrm{H})$ were measured by HPLC after Triton X-100 permeabilization of coronary endothelium and collection of coronary effluent. $\mathrm{NADP}(\mathrm{H})$ was depleted $\sim 80 \%$ in vehicle-treated hearts undergoing I/R. In $10 \mu \mathrm{M}$ $78 \mathrm{c}$-treated hearts, only $\sim 20 \%$ depletion of $\mathrm{NADP}(\mathrm{H})$ occurred, likely through inhibition of CD38. $* * * P<0.001$ vs. control; ${ }^{\dagger \dagger \dagger} P<0.001$ vs. control (mean \pm S.E.M., $n=4$ )

I/R. Although $1 \mu \mathrm{M} 78 \mathrm{c}$ had no effect on the preservation of NOS-dependent CF, preservation was observed at 2.5, 5, and $10 \mu \mathrm{M}$, with values of $46.7 \% \pm 0.9 \%, 78.8 \% \pm 3.0 \%$, and $92.0 \% \pm 4.1 \%$, respectively (Fig. $4 \mathrm{~B}$ ).

Endothelial Levels of $\operatorname{NADP}(\mathbf{H})$. Previously, we measured levels of $\mathrm{NADP}(\mathrm{H})$ from the coronary endothelium of wild-type (WT) and CD38 ${ }^{-1-}$ hearts undergoing I/R. In those experiments, we found that levels of $\operatorname{NADP}(\mathrm{H})$ were severely depleted in WT hearts but were largely protected in CD38 ${ }^{-/-}$ hearts (Boslett et al., 2018a). To determine whether 78c could prevent the $\mathrm{NADP}(\mathrm{H})$ depletion seen in WT hearts after $\mathrm{I} / \mathrm{R}$, $78 \mathrm{c}$ was infused at $10 \mu \mathrm{M}$ to ensure complete CD38 inhibition and the endothelial levels of $\mathrm{NADP}(\mathrm{H})$ were measured. Compared with their respective nonischemic levels, postischemic levels of endothelial $\mathrm{NADP}(\mathrm{H})$ were greatly decreased to just $25 \%$ of basal levels. This demonstrates that there is marked depletion of $\mathrm{NADP}(\mathrm{H})$ from the coronary endothelium. With $78 \mathrm{c}$, the percentage of recovery was nearly $80 \%$ of basal levels (Fig. 5). Thus, 78c treatment is highly effective in preserving endothelial $\mathrm{NADP}(\mathrm{H})$ levels in $\mathrm{I} / \mathrm{R}$.

Effect of 78c Treatment on Myocardial Tetrahydrobiopterin Content. With 78c-mediated protection of total $\mathrm{CF}$, NOS-dependent $\mathrm{CF}$, and endothelial $\mathrm{NADP}(\mathrm{H})$ against $\mathrm{I} / \mathrm{R}$, we sought to determine how the levels of the important NOS cofactor tetrahydrobiopterin $\left(\mathrm{BH}_{4}\right)$ were affected by $\mathrm{I} / \mathrm{R}$ with and without 78c treatment. In vehicle-treated hearts undergoing I/R, $\mathrm{BH}_{4}$ levels fell by $\sim 65 \%$ from $5.1 \pm 0.3$ to $1.8 \pm 0.4 \mathrm{pmol} / \mathrm{mg}$ protein. With treatment of hearts with $10 \mu \mathrm{M} 78 \mathrm{c}$ prior to $\mathrm{I} / \mathrm{R}$, postischemic $\mathrm{BH}_{4}$ levels were $3.9 \pm 0.6 \mathrm{pmol} / \mathrm{mg}$ protein, demonstrating clear protection of $\mathrm{BH}_{4}$ by CD38 inhibition (Fig. 6).

Effect of CD38 Inhibition on Levels of Myocardial $\mathbf{N A D}(\mathbf{P})^{+}$and $\left(\mathbf{2}^{\prime}\right.$-P)-ADPR. As another measure of CD38 activation and inhibition, we assayed the levels of CD38 substrates $\mathrm{NAD}(\mathrm{P})^{+}$and products $\left(2^{\prime}-\mathrm{P}\right)$-ADPR from hearts

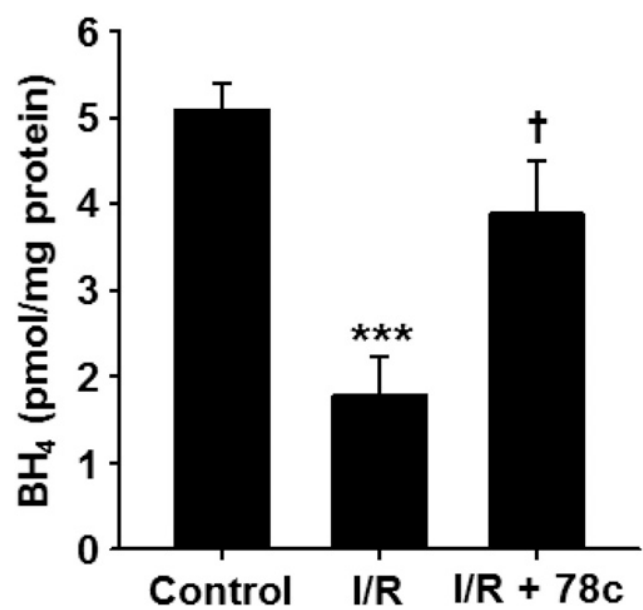

Fig. 6. $\mathrm{BH}_{4}$ levels in hearts undergoing $\mathrm{I} / \mathrm{R}$ with and without $78 \mathrm{c}$ treatment. $\mathrm{BH}_{4}$ levels in hearts subjected to 30 -minute ischemia/ 30 -minute reperfusion with and without $78 \mathrm{c}$ treatment $(10 \mu \mathrm{M})$ were compared with levels in nonischemic hearts (control). In untreated hearts, $\mathrm{BH}_{4}$ levels fell by $\sim 65 \%$ compared with nonischemic control hearts. With $78 \mathrm{c}$ treatment, $\mathrm{BH}_{4}$ depletion was greatly prevented (only $20 \%$ depletion). $* * * P<0.001$ vs. control; ${ }^{\dagger} P<0.05$ vs. I/R (mean \pm S.E.M., $n=5$ ).

undergoing control perfusion or $\mathrm{I} / \mathrm{R}$ with and without CD38 inhibition with $10 \mu \mathrm{M} 78 \mathrm{c}$. We were able to identify and resolve many nucleotides including $\mathrm{NAD}(\mathrm{P})^{+}$and $\left(2^{\prime}-\mathrm{P}-\right) \mathrm{ADPR}$ with long retention times by taking advantage of ion-pairing reversed phase chromatography, a technique related to ionexchange chromatography that allows for enhanced retention of charged metabolites. The HPLC method was fairly sensitive with an approximate $1 \mu \mathrm{M}$ limit of detection for all nucleotides tested. However, this was enhanced by SPE of nucleotides prior to HPLC, with subsequent sample lyophilization and resuspension in lower volumes, allowing an improved limit of detection of $\sim 200 \mathrm{nM}$. Consistent with previous experiments in this area, we observed depletion of CD38 substrates $\mathrm{NAD}^{+}$ and $\mathrm{NADP}^{+}$of $\sim 30 \%$ and $50 \%$, respectively. In the same tissue samples, we found that the levels of both $\mathrm{NAD}^{+}$-derived ADPR and $\mathrm{NADP}^{+}$-derived $2^{\prime}$-P-ADPR increased, with less of an effect on ADPR compared with 2 '-P-ADPR (1.5-fold vs. 5-fold). These increases were mediated by CD38 activation, as the preischemic treatment of hearts with $10 \mu \mathrm{M} 78 \mathrm{c}$ prevented the I/R-induced increase in levels of both metabolites (Figs. 7 and 8). In these experiments, post-I/R levels of each CD38-derived product were similar to basal control levels, indicating that $78 \mathrm{c}$ fully blocked the CD38 activation and product formation in I/R hearts. We also searched for CD38-derived signaling molecules (2'-P-)cADPR and NAADP, but we found no evidence of either from heart tissue.

CD38 Inhibition Preserves High-Energy Phosphates. Using the HPLC method for $\mathrm{NAD}(\mathrm{P})^{+}$and $\left(2^{\prime}-\mathrm{P}-\right) \mathrm{ADPR}$, we were also able to detect and quantitate ATP, ADP, and AMP levels in the nonischemic and postischemic hearts. Preischemic levels of ATP and ADP were $11.0 \pm 0.9$ and $5.6 \pm 0.1 \mu \mathrm{mol} / \mathrm{g}$ tissue, respectively, with reduction after $\mathrm{I} / \mathrm{R}$ to $4.38 \pm 0.16$ and $4.03 \pm 0.20 \mu \mathrm{mol} / \mathrm{g}$ tissue, respectively. These magnitudes of ATP and ADP depletion are consistent with prior reports (Neely and Grotyohann, 1984; Imahashi et al., 2004). Interestingly, with $78 \mathrm{c}$ treatment prior to $\mathrm{I} / \mathrm{R}$, these levels were largely preserved, with levels of $8.5 \pm 1.6$ and $5.2 \pm 0.3 \mu \mathrm{mol} / \mathrm{g}$ tissue, respectively, for ATP and ADP (Fig. 8B). Higher postischemic levels of ATP and ADP are consistent with the increased 

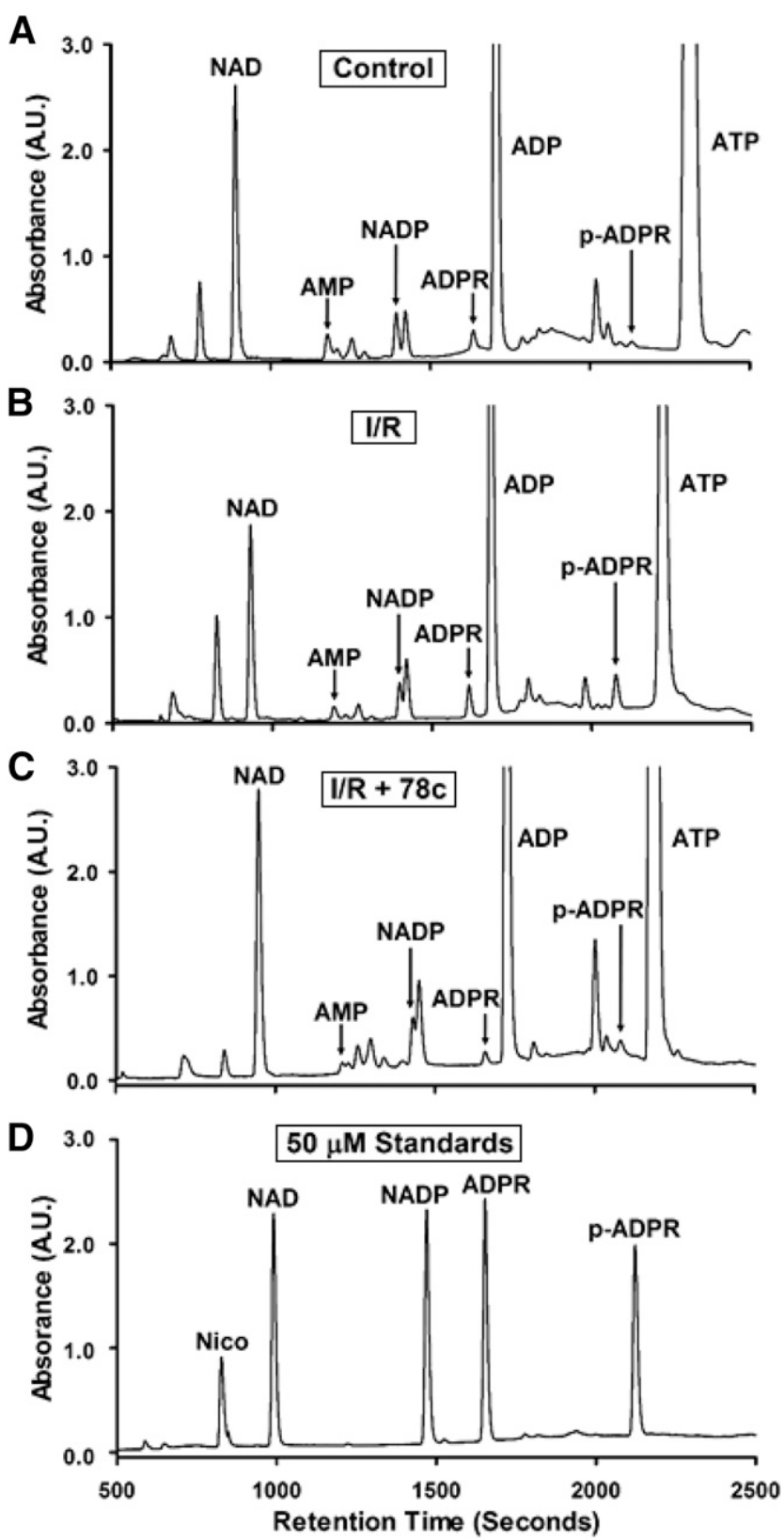

Fig. 7. Representative chromatograms of CD38 substrates and products from hearts. CD38 substrates $\mathrm{NAD}(\mathrm{P})^{+}$and products $\left(2^{\prime}-\mathrm{P}-\right) \mathrm{ADPR}$ and nicotinamide (nico) were measured by HPLC in hearts undergoing control perfusion (control) (A), I/R (B), or I/R plus $10 \mu \mathrm{M} 78 \mathrm{c}(\mathrm{I} / \mathrm{R}+78 \mathrm{c})(\mathrm{C})$. Representative chromatograms for each are shown (A-C), along with a chromatogram of a standard mixture of $50 \mu \mathrm{M}$ of each analyte (D).

recovery of contractility seen in Fig. 3 . Whereas ATP and ADP levels were decreased by I/R and preserved with CD38 inhibition, AMP levels were not significantly altered in either condition relative to control hearts, with control levels of $0.18 \pm 0.01 \mu \mathrm{mol} / \mathrm{g}, \mathrm{I} / \mathrm{R}$ levels of $0.16 \pm 0.02 \mu \mathrm{mol} / \mathrm{g}$, and $10 \mu \mathrm{M} 78 \mathrm{c}$-treated I/R levels of $0.14 \pm 0.03 \mu \mathrm{mol} / \mathrm{g}$.

Tissue Uptake, Levels, and Partitioning of 78c. After characterizing the dose-dependent protective effects of 78c, we performed measurements of $78 \mathrm{c}$ in hearts treated with 1-10 $\mu \mathrm{M} 78 \mathrm{c}$. As we failed to find cardiac protection with $1 \mu \mathrm{M} 78 \mathrm{c}$, we wanted to better understand the tissue uptake and washout kinetics in the isolated heart. Infusions of $78 \mathrm{c}$ to isolated hearts were performed, as in the prior functional studies, for 10 minutes after a 20-minute period of stabilization. After either 2 minutes of additional drug-free perfusion to clear the vasculature or after 30 minutes of ischemia/30 minutes of reperfusion, hearts were frozen in liquid nitrogen for the HPLC analysis of 78c. These experiments showed that $78 \mathrm{c}$ infusion increased tissue $78 \mathrm{c}$ concentrations to a level very close to the final concentration of delivery. After the 2-minute washout period, postinfusion $78 \mathrm{c}$ levels in heart tissue were approximately $15.85 \pm 1.43,6.99 \pm 1.34,3.54 \pm 0.80$, and $2.63 \pm 0.29 \mathrm{nmol} / \mathrm{g}$ tissue for 10, 5, 2.5, and $1 \mu \mathrm{M} \mathrm{78c} \mathrm{treatment,} \mathrm{respectively} \mathrm{(Fig.} \mathrm{9).}$ Thus, tissue uptake of $78 \mathrm{c}$ is efficient and the drug is retained in the heart.

After 30 minutes of ischemia/30 minutes of reperfusion, $78 \mathrm{c}$ levels decreased considerably (around 50\%) to $7.91 \pm 0.20$, $3.49 \pm 1.13,1.93 \pm 0.19$, and $1.17 \pm 0.04 \mathrm{nmol} / \mathrm{g}$ tissue for 10 , $5,2.5$, and $1 \mu \mathrm{M} 78 \mathrm{c}$, respectively (Fig. 9). However, levels of $78 \mathrm{c}$ even at the lowest dose of $1 \mu \mathrm{M}$ still well exceeded those required for full CD38 inhibition based on the in vitro data. With a lack of cardiac protection at $1 \mu \mathrm{M} 78 \mathrm{c}$, we reasoned that there were other factors, such as nonspecific protein or membrane sequestration, limiting the free levels of $78 \mathrm{c}$ in tissue. To test this, we performed an aqueous, $\mathrm{pH}$ neutral extraction of 78c from $10 \mu \mathrm{M} 78 \mathrm{c}-$ treated hearts (control and $\mathrm{I} / \mathrm{R}$ ) and found that the free aqueous tissue levels of $78 \mathrm{c}$ were less than $5 \%$ of the total measured drug concentration, with levels of $0.68 \pm 0.01 \mathrm{nmol} / \mathrm{g}$ tissue preischemia and $0.15 \pm 0.02 \mathrm{nmol} / \mathrm{g}$ tissue post-I/R. With the lower doses of 78c, particularly $1 \mu \mathrm{M}$ (where no protective effect was seen), we reason that the effective, free aqueous concentration of $78 \mathrm{c}$ was below that required for $\mathrm{CD} 38$ inhibition.

Infarct Size. Hearts tested for the recovery of contractile function were allowed to reperfuse for a total of 120 minutes. Hearts were then sectioned and TTC stained for delineation of viable and infarcted tissue. In vehicle-treated hearts, we measured an average infarct size of $40.9 \% \pm 5.8 \%$. We found that, like with the recovery of contractile function, $78 \mathrm{c}$ dosedependently prevented myocardial infarction after 30 minutes of ischemia, with values of $33.7 \% \pm 2.8 \%, 29.2 \% \pm 5.1 \%, 21.3 \%$ $\pm 3.3 \%, 9.4 \% \pm 2.0 \%$, and $14.8 \% \pm 3.0 \%$ for $1,2.5,5,10$, and $50 \mu \mathrm{M} 78 \mathrm{c}$, respectively (Fig. 10).

\section{Discussion}

CD38 has been implicated in many physiologic and pathophysiological processes, including chronic lymphocytic leukemia (Ibrahim et al., 2001), diabetes (Kato et al., 1999; Han et al., 2002), metabolic syndrome and aging (Chini, 2009; Camacho-Pereira et al., 2016), social behavior (Jin et al., 2007), the immune response (Cockayne et al., 1998; PartidaSánchez et al., 2001), stroke (Choe et al., 2011), and myocardial I/R (Reyes et al., 2015; Guan et al., 2016; Boslett et al., 2017,2018 a). Thus, there is a great need for the development of CD38 inhibitors (Choe et al., 2011; Kellenberger et al., 2011; Moreau et al., 2013; Wang et al., 2014; Becherer et al., 2015; Blacher et al., 2015; Haffner et al., 2015). Given the breadth of (patho)physiology involving CD38, the recent discovery of high-potency thiazoloquin(az)olin(on)e CD38 inhibitors has great therapeutic potential (Haffner et al., 2015).

In myocardial $\mathrm{I} / \mathrm{R}$, we have demonstrated a role for CD38 in the degradation of myocardial and endothelial $\mathrm{NAD}(\mathrm{P})(\mathrm{H})$ (Reyes et al., 2015; Boslett et al., 2017, 2018a,b). Pharmacological 

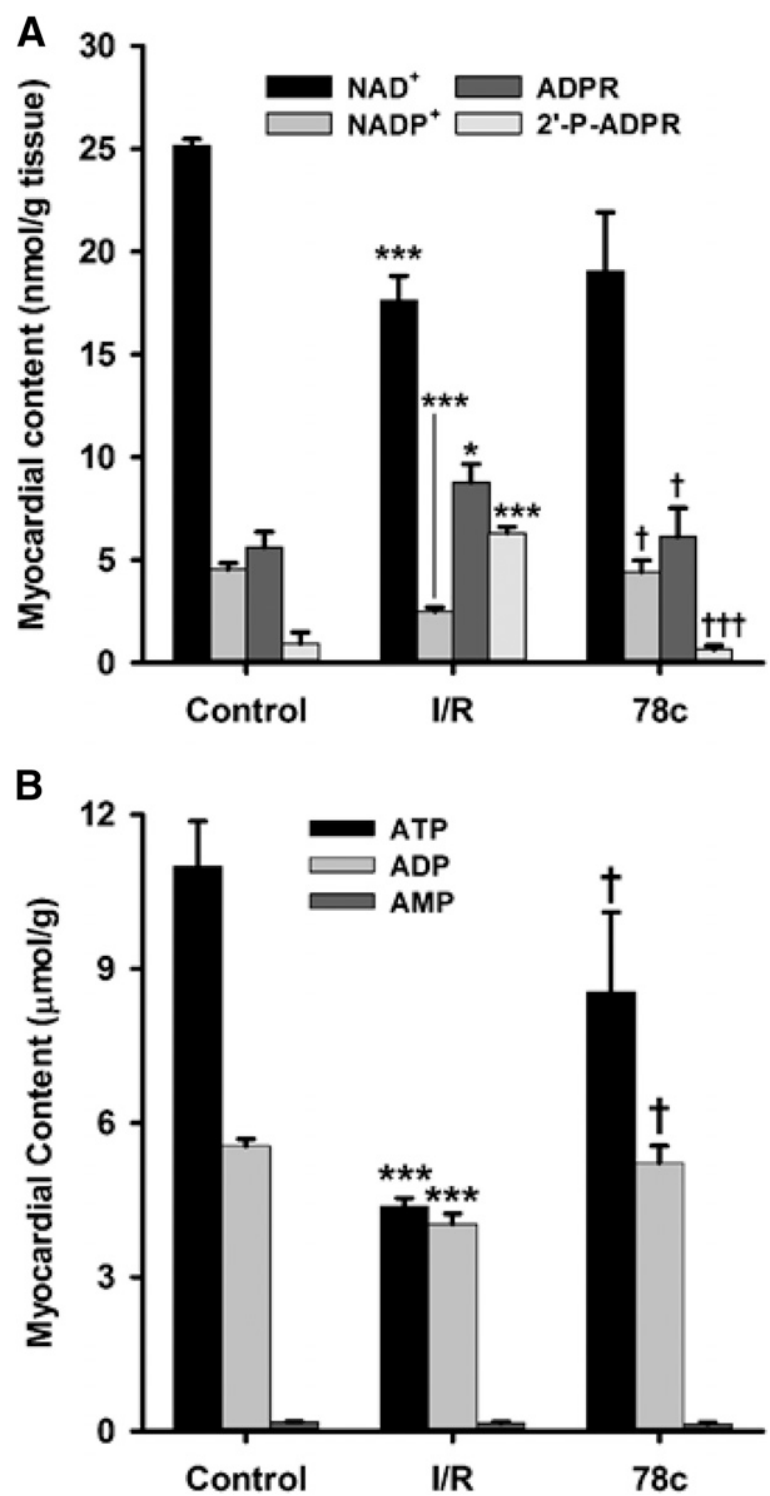

Fig. 8. Tissue nucleotide levels. (A) $\mathrm{NAD}(\mathrm{P})^{+}$and (2'-P-)ADPR levels. With $\mathrm{I} / \mathrm{R}$, levels of $\mathrm{NAD}(\mathrm{P})^{+}$decreased compared with the control, with increased levels of CD38 enzymatic products (2'-P-)ADPR. Preischemic treatment with $10 \mu \mathrm{M} 78 \mathrm{c}$ prevented the $\mathrm{NAD}(\mathrm{P})^{+}$depletion and enhanced (2'-P-)ADPR production seen with I/R. (B) ATP, ADP, and AMP levels. With I/R, ATP and ADP levels fell greater than 50\% and 30\%, respectively, in vehicle-treated hearts compared with nonischemic controls. Postischemic levels of these nucleotides were higher in 78c-treated hearts, consistent with increased recovery of left ventricular function. AMP levels were unaffected by I/R. $* P<0.05$ vs. control; $* * * P<0.001$ vs. control; ${ }^{\dagger} P<$ 0.05 vs. I/R; ${ }^{\dagger \dagger} P<0.001$ vs. I/R (mean \pm S.E.M., $n=5$ ).

blocking or genetic deletion of CD38 protects the heart against $\mathrm{I} / \mathrm{R}$. Since many enzymes require $\mathrm{NAD}(\mathrm{P})(\mathrm{H})$ as substrate, depletion of $\mathrm{NAD}(\mathrm{P})(\mathrm{H})$ by CD38 activation may affect several key processes, including mitochondrial respiration, reductive biosynthesis, and signaling processes. For example, sirtuins are important NAD-requiring signaling enzymes that are affected by low cellular $\mathrm{NAD}^{+}$levels caused by CD38 activation (Camacho-Pereira et al., 2016; Guan et al., 2016). Another example is glutathione reductase, which catalyzes the conversion of oxidized glutathione to two molecules of reduced glutathione at the expense of NADPH. Interestingly, CD $38^{-1-}$ mice have higher glutathione levels under normal

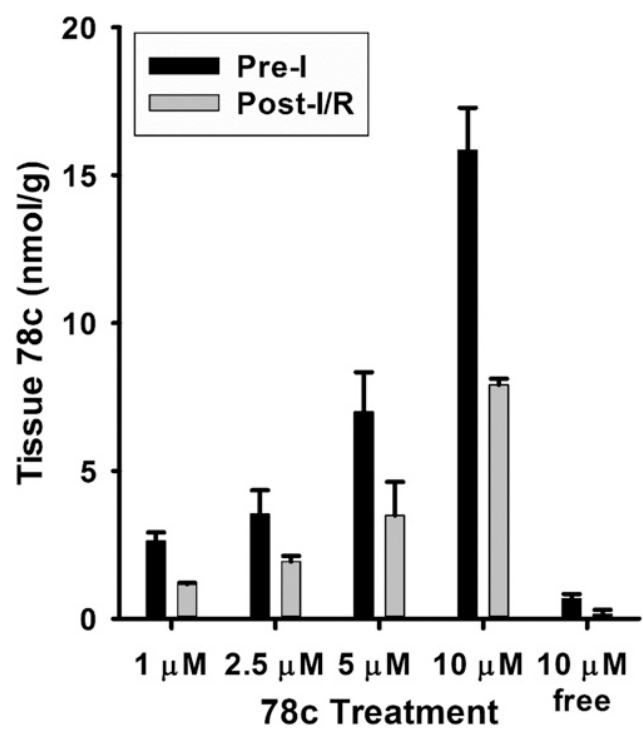

Fig. 9. Tissue 78c levels after preischemic delivery and 30-minute ischemia/30-minute reperfusion. Total tissue $78 \mathrm{c}$ levels were assayed after delivery and a short washout period to clear the vasculature (preischemia) and after delivery and 30-minute ischemia/30-minute reperfusion (postischemia). 78c uptake was efficient, as levels equal to or greater than the delivered concentration were achieved in tissue. An additional 30-minute ischemia/30-minute reperfusion led to an $\sim 50 \%$ decline of the preischemic levels. Free levels were also assessed for the $10-\mu \mathrm{M}$ dose, which showed that most of the delivered $78 \mathrm{c}$ was in a sequestered nonfree form (mean \pm S.E.M., $n=4)$.

and postischemic conditions compared with WT controls (Boslett et al., 2018a). Our studies have shown that eNOS, which requires NADPH in the vascular synthesis of vasodilatory NO, is impaired after an ischemia by CD38mediated NADP $(\mathrm{H})$ depletion (Reyes et al., 2015). The variety of potential processes affected by activated CD38 makes investigation and characterization of novel CD38 inhibitors very important.

We tested the lead compound, 78c, developed from the new class of thiazoloquin(az)olin(on)e CD38 inhibitors. We did this first in vitro with rCD38 to determine the potency and mechanism of CD38 inhibition by 78c. We then characterized the effects of $78 \mathrm{c}$ in a model of myocardial I/R injury with both metabolic and functional measurements. A similar study was performed previously with the flavonoid CD38 inhibitor, luteolinidin. We observed that luteolinidin, which occurs naturally in some plant species such as sorghum (Awika et al., 2004), had a $K_{\mathrm{i}}$ of around $10 \mu \mathrm{M}$ (Boslett et al., 2017). Using the same assay, we found that $78 \mathrm{c}$ is a much more potent CD38 inhibitor than the flavonoids ( $>1000$-fold), with a $K_{\mathrm{i}}$ of $9 \mathrm{nM}$ (Fig. 2).

Previous studies demonstrated large losses of myocardial contractile function, as well as total and NOS-dependent CF with 30-minute ischemia/30-minute reperfusion in the isolated heart (Reyes et al., 2015; Boslett et al., 2017, 2018a). Consistent with this, postischemic left ventricular function was greatly reduced after 30-minute ischemia while total and NOSdependent $\mathrm{CF}$ were also significantly lower. With 78c treatment, we observed dose-dependent protection of each of these parameters from 2.5 to $50 \mu \mathrm{M} \mathrm{78c} \mathrm{(Figs.} 3$ and 4). This is consistent with studies of other CD38 inhibitors and the CD38 ${ }^{-1-}$ heart, which also demonstrated increased recovery of total and NOS-dependent CF (Reyes et al., 2015; Boslett et al., 2017, 2018a). 


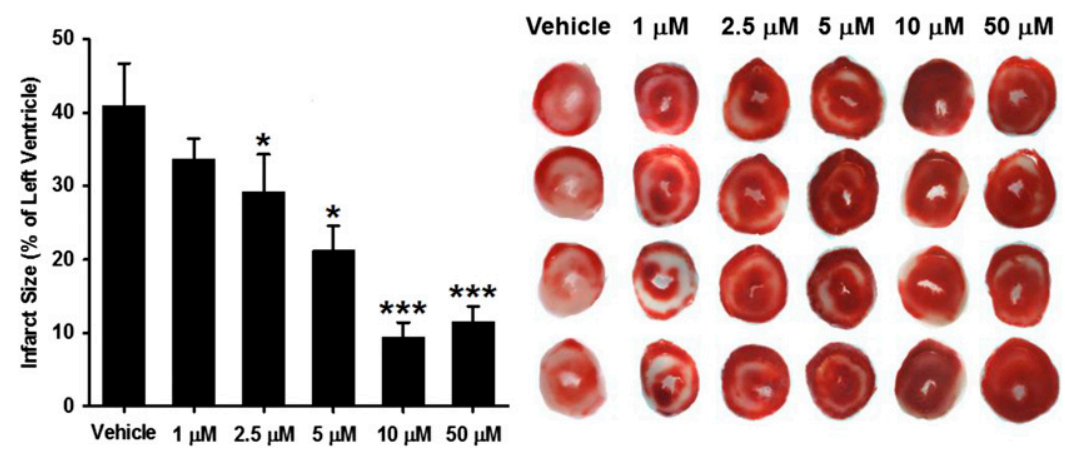

Fig. 10. Effect of $78 \mathrm{c}$ on infarct size. Infarct size was measured after 30-minute ischemia/120-minute reperfusion in hearts dosed preischemia with vehicle ( $0.1 \%$ DMSO) or 1 , $2.5,5,10$, or $50 \mu \mathrm{M} 78 \mathrm{c}$. $78 \mathrm{c}$ at $2.5,5,10$, and $50 \mu \mathrm{M}$ levels significantly decreased infarct size compared with vehicle. $* P<0.05$; $* * * P<0.001$ vs. vehicle (mean \pm S.E.M., $n=5-9$ ).
$\mathrm{NADP}(\mathrm{H})$ levels in the coronary endothelium were $\sim 80 \%$ decreased after I/R. This was largely blocked by preischemic treatment of hearts with $10 \mu \mathrm{M} 78 \mathrm{c}$ (Fig. 5). This large NADP (H) depletion contributes to postischemic eNOS dysfunction and its prevention by CD38 inhibition preserves eNOSdependent vasodilatory function. This profound local NAD (P)H depletion may cause impairment of NADPH-requiring enzymes, such as those in the $\mathrm{BH}_{4}$ recycling and de novo synthesis pathways. With loss of endothelial NADPH, normal levels of $\mathrm{BH}_{4}$, which are depleted through oxidation in $\mathrm{I} / \mathrm{R}$ (Dumitrescu et al., 2007; De Pascali et al., 2014), cannot be recovered and maintained. We found that $\mathrm{BH}_{4}$ was markedly depleted by I/R and that CD38 inhibition with 78c was highly effective in preserving $\mathrm{BH}_{4}$ after I/R (Fig. 6). This may be due to impaired function of NADPH-requiring enzymes sepiapterin reductase and/or dihydrofolate reductase, essential enzymes in these pathways (Bailey and Ayling, 2009; Yang et al., 2013). Thus, CD38 activation, through endothelial NADPH depletion and subsequent contribution to low $\mathrm{BH}_{4}$ levels, acts as a trigger for endothelial dysfunction caused by impaired NOS-dependent NO production.

We assessed CD38 activation by measuring degradation of CD38 substrates, $\mathrm{NAD}(\mathrm{P})^{+}$, and formation of the resultant products, (2'-P-)ADPR, after I/R, and tested the efficacy of $78 \mathrm{c}$ to block each process (Figs. 7 and 8A). In untreated hearts undergoing I/R, postischemic levels of $\mathrm{NAD}^{+}$and $\mathrm{NADP}^{+}$dropped by $30 \%$ and $50 \%$, respectively. In these hearts, levels of the CD38 products ADPR and 2'-P-ADPR increased, consistent with CD38 activation. Treatment of hearts with 78c was effective at blocking I/R-induced CD38 activation, resulting in preserved $\mathrm{NAD}(\mathrm{P})^{+}$and $\left(2^{\prime}-\mathrm{P}-\right) \mathrm{ADPR}$ levels near those of nonischemic hearts. Although CD38 is an enzyme that primarily produces "linear" (2'-P-)ADPR, it can also produce two calcium-mobilizing second messengers in lesser amounts: (2'-P-)cADPR (Vu et al., 1996; Kato et al., 1999; Partida-Sánchez et al., 2001; Deshpande et al., 2005; Chini, 2009) and NAADP (Chini et al., 2002) (Fig. 1). In assaying the myocardial levels of $\mathrm{NAD}(\mathrm{P})^{+}$and $\left(2^{\prime}-\mathrm{P}-\right) \mathrm{ADPR}$, we also attempted to measure (2'-P-)cADPR and NAADP but these were undetectable, likely due to the limited sensitivity of the assay ( $200 \mathrm{nM}$ limit of detection) and the low concentrations of these signaling molecules. Nevertheless, production of these compounds might increase with CD38 activation in I/R. This could represent an additional mechanism contributing to I/R injury, which is partially due to perturbed $\mathrm{Ca}^{2+}$ homeostasis of cardiac myocytes and endothelial cells (Zimmerman and Hulsmann, 1966; Ladilov et al., 2000; Garcia-Dorado et al., 2012).
CD38 inhibition also preserved the levels of high-energy phosphates, ATP and ADP, with significantly higher levels after I/R with $78 \mathrm{c}$ treatment compared with vehicle (Fig. 8B). This might occur indirectly through maintained mitochondrial respiration, which would be expected with protected $\mathrm{NAD}(\mathrm{H})$ levels and higher $\mathrm{CF}$ and increased $\mathrm{O}_{2}$ delivery. The increased contractile function seen with $78 \mathrm{c}$ treatment is consistent with this, as is the greatly lessened left ventricular infarct size also seen with $78 \mathrm{c}$ treatment (Fig. 10). Compared with a previous study with CD38 ${ }^{-1-}$ hearts, treatment of hearts with $78 \mathrm{c}$ at a dose of $10 \mu \mathrm{M}$ prior to I/R similarly protects the heart from infarction (Boslett et al., 2018a).

For physiologic protection, higher concentrations (2.5-50 $\mu \mathrm{M})$ were required than expected from the in vitro data. We measured tissue uptake and levels of $78 \mathrm{c}$ in the heart and found that tissue uptake was efficient, as tissue drug concentrations essentially matched the delivered $78 \mathrm{c}$ concentration. Washout in the reperfusion period $(\sim 50 \%)$ occurred, but adequate levels for inhibition remained even after 30 minutes of reperfusion. We questioned whether the delivered drug was bound or sequestered within the tissue and not in a freely available form in the aqueous phase. Thus, we measured total and free drug concentrations in hearts receiving $10 \mu \mathrm{M} 78 \mathrm{c}$ (Fig. 9), and we determined that much of the drug (at least 95\%) was in a nonfree state, likely protein bound, sequestered in membranes, or both. Overall, we determined that $78 \mathrm{c}$ is a cell-permeable compound with favorable rapid absorption properties. Previously, the group that discovered the thiazoloquin(az)olin(on)es as CD38 inhibitors determined 78c to be a lipophilic compound (with a ChromLog D value of 3.22 at pH 7.4 based on the octanol/water partition), which likely contributes to its high permeability (Haffner et al., 2015).

The thiazoloquin(az)olin(on)es such as $78 \mathrm{c}$ represent the highest affinity class of CD38 inhibitors discovered. As such, they should prove invaluable in studies determining the role of CD38 in physiology and disease (Aksoy et al., 2006; Barbosa et al., 2007; Camacho-Pereira et al., 2016). Although the CD38 $8^{-1-}$ mouse is a powerful tool to explore CD38 function, there can be unanticipated compensatory mechanisms for maintaining homeostasis in genetically modified mice. Thus, the availability of a high-affinity specific inhibitor is of immense value. As an example of this, the effect of CD38 on the aging process was demonstrated initially using a genetic approach to show that CD38 ${ }^{-/-}$ mice were resistant to aging compared with WT mice (Camacho-Pereira et al., 2016), which was then confirmed by a pharmacologic approach demonstrating a robust antiaging effect of 78c (Tarrago et al., 2018). 
Overall, we demonstrate the ability of the highly potent CD38 inhibitor $78 \mathrm{c}$ to effect cardiac protection in an ex vivo model of I/R. Consistent with previous studies with the flavonoid CD38 inhibitor, luteolinidin, and the CD38 ${ }^{-/-}$ mouse (Boslett et al., 2017, 2018a), we observed protection of postischemic contractile function and NOS-dependent endothelial vasodilatory function as well as decreased infarct size with $78 \mathrm{c}$ treatment. The results suggest that $78 \mathrm{c}$ could be of great value as a tool to study the role of CD38 in disease, with potential for clinical translation in cardiovascular and other metabolic diseases.

\section{Authorship Contributions}

Participated in research design: Boslett, Zweier.

Conducted experiments: Boslett, Reddy, Alzarie.

Performed data analysis: Boslett, Zweier.

Wrote or contributed to the writing of the manuscript: Boslett, Zweier.

\section{References}

Aksoy P, White TA, Thompson M, and Chini EN (2006) Regulation of intracellular levels of NAD: a novel role for CD38. Biochem Biophys Res Commun 345:1386-1392. Awika JM, Rooney LW, and Waniska RD (2004) Properties of 3-deoxyanthocyanins from sorghum. J Agric Food Chem 52:4388-4394.

Bailey SW and Ayling JE (2009) The extremely slow and variable activity of dihydrofolate reductase in human liver and its implications for high folic acid intake. Proc Natl Acad Sci USA 106:15424-15429.

Barbosa MTP, Soares SM, Novak CM, Sinclair D, Levine JA, Aksoy P, and Chini EN (2007) The enzyme CD38 (a NAD glycohydrolase, EC 3.2.2.5) is necessary for the development of diet-induced obesity. FASEB J 21:3629-3639.

Becherer JD, Boros EE, Carpenter TY, Cowan DJ, Deaton DN, Haffner CD, Jeune MR, Kaldor IW, Poole JC, Preugschat F, et al. (2015) Discovery of 4-amino-8quinoline carboxamides as novel, submicromolar inhibitors of NAD-hydrolyzing enzyme CD38. J Med Chem 58:7021-7056.

Berthelier V, Tixier JM, Muller-Steffner H, Schuber F, and Deterre P (1998) Human CD38 is an authentic NAD(P)+ glycohydrolase. Biochem $J$ 330:1383-1390.

Blacher E, Ben Baruch B, Levy A, Geva N, Green KD, Garneau-Tsodikova S, Fridman M, and Stein R (2015) Inhibition of glioma progression by a newly discovered CD38 inhibitor. Int $J$ Cancer 136:1422-1433.

Boslett J, Helal M, Chini E, and Zweier JL (2018a) Genetic deletion of CD38 confers post-ischemic myocardial protection through preserved pyridine nucleotides. $J \mathrm{Mol}$ Cell Cardiol 118:81-94.

Boslett J, Hemann C, Christofi FL, and Zweier JL (2018b) Characterization of CD38 in the major cell types of the heart: endothelial cells highly express CD38 with activation by hypoxia-reoxygenation triggering $\mathrm{NAD}(\mathrm{P}) \mathrm{H}$ depletion. Am J Physiol Cell Physiol 314:C297-C309.

Boslett J, Hemann C, Zhao YJ, Lee HC, and Zweier JL (2017) Luteolinidin protects the postischemic heart through CD38 inhibition with preservation of $\mathrm{NAD}(\mathrm{P})(\mathrm{H})$. $J$ Pharmacol Exp Ther 361:99-108.

Camacho-Pereira J, Tarragó MG, Chini CCS, Nin V, Escande C, Warner GM, Puranik AS, Schoon RA, Reid JM, Galina A, et al. (2016) CD38 dictates age-related NAD decline and mitochondrial dysfunction through an SIRT3-dependent mechanism. Cell Metab 23:1127-1139.

Chini EN (2009) CD38 as a regulator of cellular NAD: a novel potential pharmacological target for metabolic conditions. Curr Pharm Des 15:57-63.

Chini EN, Chini CCS, Kato I, Takasawa S, and Okamoto H (2002) CD38 is the major enzyme responsible for synthesis of nicotinic acid-adenine dinucleotide phosphate in mammalian tissues. Biochem $J$ 362:125-130.

Choe CU, Lardong K, Gelderblom M, Ludewig P, Leypoldt F, Koch-Nolte F, Gerloff C and Magnus T (2011) CD38 exacerbates focal cytokine production, postischemic inflammation and brain injury after focal cerebral ischemia [published correction appears in PLoS One (2011) 6. DOI: 10.1371/annotation/295c388d-013d-4bb9-b4e4da8e88317594]. PLoS One 6:e19046.

Cockayne DA, Muchamuel T, Grimaldi JC, Muller-Steffner H, Randall TD, Lund FE, Murray R, Schuber F, and Howard MC (1998) Mice deficient for the ectonicotinamide adenine dinucleotide glycohydrolase CD38 exhibit altered humoral immune responses. Blood 92:1324-1333.

De Pascali F, Hemann C, Samons K, Chen CA, and Zweier JL (2014) Hypoxia and reoxygenation induce endothelial nitric oxide synthase uncoupling in endothelial cells through tetrahydrobiopterin depletion and S-glutathionylation. Biochemistry 53:3679-3688.

Deshpande DA, White TA, Dogan S, Walseth TF, Panettieri RA, and Kannan MS (2005) CD38/cyclic ADP-ribose signaling: role in the regulation of calcium homeostasis in airway smooth muscle. Am J Physiol Lung Cell Mol Physiol 288: L773-L788.

Dumitrescu C, Biondi R, Xia Y, Cardounel AJ, Druhan LJ, Ambrosio G, and Zweier $\mathrm{JL}(2007)$ Myocardial ischemia results in tetrahydrobiopterin $\left(\mathrm{BH}_{4}\right)$ oxidation with impaired endothelial function ameliorated by $\mathrm{BH}_{4}$. Proc Natl Acad Sci USA 104: 15081-15086.

Garcia-Dorado D, Ruiz-Meana M, Inserte J, Rodriguez-Sinovas A, and Piper HM (2012) Calcium-mediated cell death during myocardial reperfusion. Cardiovasc Res 94:168-180.
Giraldez RR, Panda A, and Zweier JL (2000) Endothelial dysfunction does not require loss of endothelial nitric oxide synthase. Am J Physiol Heart Circ Physiol 278: H2020-H2027.

Graeff R, Liu Q, Kriksunov IA, Hao Q, and Lee HC (2006) Acidic residues at the active sites of CD38 and ADP-ribosyl cyclase determine nicotinic acid adenine dinucleotide phosphate (NAADP) synthesis and hydrolysis activities. J Biol Chem 281:28951-28957.

Graeff RM and Lee HC (2013) Determination of ADP-ribosyl cyclase activity, cyclic $\mathrm{ADP}-$ ribose, and nicotinic acid adenine dinucleotide phosphate in tissue extracts. Methods Mol Biol 1016:39-56.

Guan XH, Liu XH, Hong X, Zhao N, Xiao YF, Wang LF, Tang L, Jiang K, Qian YS, Deng $\mathrm{KY}$, et al. (2016) CD38 deficiency protects the heart from ischemia/reperfusion injury through activating SIRT1/FOXOs-mediated antioxidative stress pathway. Oxid Med Cell Longev 2016:7410257.

Haffner CD, Becherer JD, Boros EE, Cadilla R, Carpenter T, Cowan D, Deaton DN, Guo Y, Harrington W, Henke BR, et al. (2015) Discovery, synthesis, and biological evaluation of thiazoloquin(az)olin(on)es as potent CD38 inhibitors. J Med Chem 58:3548-3571.

Han MK, Kim SJ, Park YR, Shin YM, Park HJ, Park KJ, Park KH, Kim HK, Jang SI, An NH, et al. (2002) Antidiabetic effect of a prodrug of cysteine, L-2-oxothiazolidine-4carboxylic acid, through CD38 dimerization and internalization. $J$ Biol Chem 277: $5315-5321$.

Ibrahim S, Keating M, Do KA, O’Brien S, Huh YO, Jilani I, Lerner S, Kantarjian HM, and Albitar M (2001) CD38 expression as an important prognostic factor in B-cell chronic lymphocytic leukemia. Blood 98:181-186.

Imahashi K, Schneider MD, Steenbergen C, and Murphy E (2004) Transgenic expression of Bcl-2 modulates energy metabolism, prevents cytosolic acidification during ischemia, and reduces ischemia/reperfusion injury. Circ Res $\mathbf{9 5}$ 734-741.

Jin D, Liu HX, Hirai H, Torashima T, Nagai T, Lopatina O, Shnayder NA, Yamada K, Noda M, Seike T, et al. (2007) CD38 is critical for social behaviour by regulating oxytocin secretion. Nature 446:41-45.

Kato I, Yamamoto Y, Fujimura M, Noguchi N, Takasawa S, and Okamoto H (1999) CD38 disruption impairs glucose-induced increases in cyclic ADP-ribose, $[\mathrm{Ca} 2+] \mathrm{i}$, and insulin secretion. $J$ Biol Chem 274:1869-1872.

Kellenberger E, Kuhn I, Schuber F, and Muller-Steffner H (2011) Flavonoids as inhibitors of human CD38. Bioorg Med Chem Lett 21:3939-3942.

Klaidman LK, Leung AC, and Adams JD Jr (1995) High-performance liquid chromatography analysis of oxidized and reduced pyridine dinucleotides in specific brain regions. Anal Biochem 228:312-317.

Ladilov Y, Schäfer C, Held A, Schäfer M, Noll T, and Piper HM (2000) Mechanism of Ca(2+ ) overload in endothelial cells exposed to simulated ischemia. Cardiovasc Res 47:394-403.

Li N, Zhu WJ, Xue XW, Zhao YJ, Lee HC, Zhang LR, and Zhang LH (2015) The synthesis of purine derivatives and its inhibitory activity on CD38 NADase. Yao Хиe Хиe Bao 50:1013-1020.

Malavasi F, Deaglio S, Funaro A, Ferrero E, Horenstein AL, Ortolan E, Vaisitti T, and Aydin S (2008) Evolution and function of the ADP ribosyl cyclase/CD38 gene family in physiology and pathology. Physiol Rev 88:841-886.

Moreau C, Liu Q, Graeff R, Wagner GK, Thomas MP, Swarbrick JM, Shuto S, Lee HC, Hao Q, and Potter BV (2013) CD38 structure-based inhibitor design using the N1-cyclic inosine 5'-diphosphate ribose template. PLoS One 8:e66247.

Neely JR and Grotyohann LW (1984) Role of glycolytic products in damage to ischemic myocardium. Dissociation of adenosine triphosphate levels and recovery of function of reperfused ischemic hearts. Circ Res 55:816-824.

Partida-Sánchez S, Cockayne DA, Monard S, Jacobson EL, Oppenheimer N, Garvy B, Kusser K, Goodrich S, Howard M, Harmsen A, et al. (2001) Cyclic ADP-ribose production by CD38 regulates intracellular calcium release, extracellular calcium influx and chemotaxis in neutrophils and is required for bacterial clearance in vivo. Nat Med 7:1209-1216.

Quarona V, Zaccarello G, Chillemi A, Brunetti E, Singh VK, Ferrero E, Funaro A Horenstein AL, and Malavasi F (2013) CD38 and CD157: a long journey from activation markers to multifunctional molecules. Cytometry B Clin Cytom 84: $207-217$.

Reyes LA, Boslett J, Varadharaj S, De Pascali F, Hemann C, Druhan LJ, Ambrosio G, El-Mahdy M, and Zweier JL (2015) Depletion of NADP(H) due to CD38 activation triggers endothelial dysfunction in the postischemic heart. Proc Natl Acad Sci USA 112:11648-11653.

Tarrago MG, Chini CCS, Kanamori KS, Warner GM, Caride A, de Oliveira GC, Rud M, Samani A, Hein KZ, Huang R, et al. (2018) A potent and specific CD38 inhibitor ameliorates age-related metabolic dysfunction by reversing tissue $\mathrm{NAD}+$ decline. Cell Metab 27:1081-1095.e10.

Vu CQ, Lu PJ, Chen CS, and Jacobson MK (1996) 2'-Phospho-cyclic ADP-ribose, a calcium-mobilizing agent derived from NADP. J Biol Chem 271:4747-4754.

Wang S, Zhu W, Wang X, Li J, Zhang K, Zhang L, Zhao YJ, Lee HC, and Zhang L (2014) Design, synthesis and SAR studies of NAD analogues as potent inhibitors towards CD38 NADase. Molecules 19:15754-15767.

Yang S, Jan YH, Gray JP, Mishin V, Heck DE, Laskin DL, and Laskin JD (2013) Sepiapterin reductase mediates chemical redox cycling in lung epithelial cells J Biol Chem 288:19221-19237.

Zimmerman AN and Hülsmann WC (1966) Paradoxical influence of calcium ions on the permeability of the cell membranes of the isolated rat heart. Nature 211: 646-647.

Address correspondence to: Jay L. Zweier, Department of Internal Medicine, Davis Heart and Lung Research Institute, College of Medicine, The Ohio State University, 473 W. 12th Ave., Columbus, OH 43210. E-mail: jay.zweier@osumc.edu 